\title{
Research Paper Factors influencing adoption of Pradhan Mantiri Fasal Bima Yojana (PMFBY) in Tamil Nadu
}

\section{P. Lakshmanan and K.R. Ashok}

ABSTRACT : The PMFBY Scheme was launched with the theme of One Nation - One Scheme. The study was conducted in Thiruvarur and Erode districts of Tamil Nadu. One hundred and eighty farmers who adopted PMFBY were selected through random sampling procedure. The respondents were interviewed using a pre-tested questionnaire for identifying factors influencing adoption of crop insurance schemes and preference of service provider for enrolment in the scheme. The study revealed that financial security, lack of scope for crop diversification and expectation of crop loss due to adverse climatic condition were the major factors influencing the adoption of PMFBY. Co-operative banks and agents at village level were preferred for enrolment in the scheme among loanee and nonloanee farmers, respectively.

KEY WORDS : Crop insurance, PMFBY, Factors, Preferences, Loanee, Non-loanee

How To Cite This PAPer : Lakshmanan, P. and Ashok, K.R. (2019). Factors influencing adoption of Pradhan Mantiri Fasal Bima Yojana (PMFBY) in Tamil Nadu . Internat. Res. J. Agric. Eco. \& Stat., 10 (1) : 27-30, DOI : 10.15740/HAS/IRJAES/10.1/27-30. Copyright@ 2019: Hind Agri-Horticultural Society. 